\title{
Geología de Bahía Culebra, Guanacaste, Costa Rica
}

\author{
Pablo Herrera Zúñiga ${ }^{1} \&$ Ana Enid Vargas ${ }^{2}$ \\ 1. Liberia, Guanacaste, Costa Rica; geol.pabloherreraz@gmail.com \\ 2. San Pedro de Montes de Oca, San José, Costa Rica; anaenid85@gmail.com \\ Recibido 03-XI-2011. Corregido 31-I-2012. Aceptado 15-II-2012.
}

\begin{abstract}
The geology of Culebra Bay, Guanacaste, Costa Rica, is composed of volcanic rocks of oceanic crust; marine sediments deposited on the slope, continental platform and superficial zones nearby to the coast, pyroclastic rocks inset with continental sediments and recent Quaternary deposits. At the base of the stratigraphy sequence the massive basalts outcrop, sometimes as pillow, from Nicoya complex with aphanitic texture with olivine phenocrysts, augites and plagioclases. Into the same formation are included intrusives of massive gabro with pyroxene and plagiogranites with phenocrysts of plagioclases and hornblendite. Then limestones outcrop from El Viejo formation formed by colonies of reefs and limestone rocks. The Montezuma formation is composed of fossiliferous sandstone, facies of sandstone with cross-lamination and facies of sandstone and lutites. The Dacitas Carbonal are composed of lavas with pumice clasts and alteration minerals. The Bagaces formation is composed of several eruptive events with ignimbrites and possibly of a sand volcaniclastic sedimentary deposit. At the top of the stratigraphic sequence are included, product of factors such as colluvial erosion, and beach sand, areas of mangrove sediments and alluvium. Rev. Biol. Trop. 60 (Suppl. 2): 213-223. Epub 2012 April 01.
\end{abstract}

Key words: Bahía Culebra, Geology, Costa Rica.

El sector de Bahía Culebra se ubica en el Pacífico Norte de Costa Rica. El área de estudio abarca más de $40 \mathrm{~km}^{2}$ y está comprendida entre el cuadrante proyección Lambert Norte 34900E/293300N, 359000E/293300N, $359000 \mathrm{E} / 283000 \mathrm{~N}$ y $349000 \mathrm{E} / 283000 \mathrm{~N}$ de la hoja cartográfica Carrillo Norte escala 1:50 000 (Fig. 1). Se caracteriza por presentar una variedad geológica con rocas de diferentes génesis con edades que van desde el Cretácico al Holoceno. La unidad geológica más antigua está formada por basaltos, plagiogranitos y gabros del Complejo de Nicoya con edad Cretácica. Otra de las unidades que ha sido objeto de mayores estudios es la Formación Bagaces, cuyas rocas presentan edades que abarcan del Mioceno Superior al Plioceno. Uno de los primeros autores en realizar el cartografiado geológico de Bahía Culebra fue Bohnenberger (1968) incluido en el mapa geológico de la hoja Carrillo Norte. Un trabajo con mayor grado de detalle fue realizado por Camacho et al. (2002) poniendo en evidencia la presencia de una mayor diversidad de rocas y formaciones geológicas en los alrededores de Bahía Culebra, describiendo y cartografiando la Formación Descartes, las facies de areniscas y lutitas de la Unidad Iguanita (asociada a la Formación Montezuma), la Unidad Dacitas Carbonal, las facies de ignimbritas y sedimentos de Bagaces y depósitos Cuaternarios constituidos por dunas inconsolidadas, coluvios, aluviones y depósitos costeros.

El objetivo de este trabajo es mostrar los principales aspectos geológicos que conforman e influencian la Bahía Culebra, haciendo una descripción litológica y estratigráfica de las rocas que afloran en el área estudiada, generando una herramienta básica para otro tipo de estudios, sean biológicos o ambientales, donde la influencia de la geología sea relevante. 


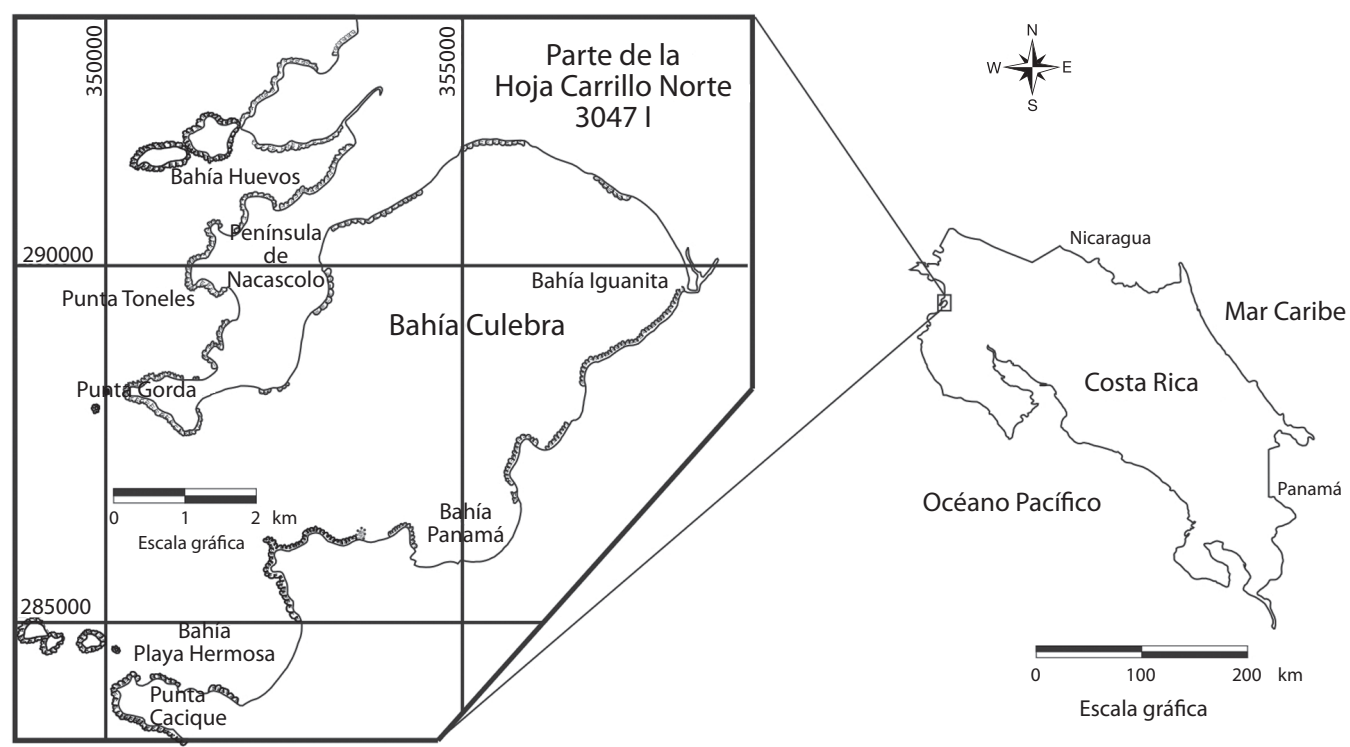

Fig. 1. Ubicación de la zona de estudio.

Fig. 1. Location of the study area.

\section{MATERIALES Y MÉTODOS}

Las formaciones y unidades de roca cartografiadas en el mapa geológico parten del principio básico de que las unidades deben basarse en criterios claros de reconocimiento en el campo. A partir de este principio se desarrollaron desde el 2002 una serie de cartografiados geológicos locales de zonas ubicadas en península de Nacascolo, Iguanita, punta Cacique, playa Hermosa y el sector de Monte del Barco para elaborar mapas de afloramientos con el objetivo de actualizar la geología local del sector de Bahía Culebra. Además, se realizaron comprobaciones de campo de afloramientos y cartografiado geológico de mapas existentes de autores que trabajaron anteriormente en la zona como Malavassi (1961), Schmidt-Effing (1974), Denyer y Arias (1993) y Camacho (2002), entre otros para, paulatinamente, realizar la correlación y la integración de los diferentes tipos de roca dentro de formaciones formales o informales.

Una vez definidas las correlaciones, la compilación cartográfica y la integración del trabajo de campo se elaboró el mapa geológico a escala 1:50000, redefiniendo contactos y extensión de las unidades de roca. La descripción litológica se realizó a partir del levantamiento de campo y se apoyó con las consultas bibliográficas, tanto para las descripciones como para la distribución estratigráfica, la cual, se definió a partir las edades de las rocas y los contactos observados.

\section{DESCRIPCIÓN LITOESTRATIGRÁFICA}

Se definen las características litológicas cartografiadas y la columna litoestratigráfica de las unidades y formaciones geológicas (Figs. 2 y 3). La geología de la zona de estudio inicia con las rocas basálticas e intrusivos del Complejo de Nicoya, la Formación El Viejo, Formación Descartes, Formación Montezuma, Unidad Carbonal, Formación Bagaces y las unidades Cuaternarias de depósitos aluviales y coluviales, dunas y depósitos de playa.

Complejo de Nicoya: Dengo (1962) nombra formalmente al Complejo de Nicoya y lo describe como un Complejo formado por 


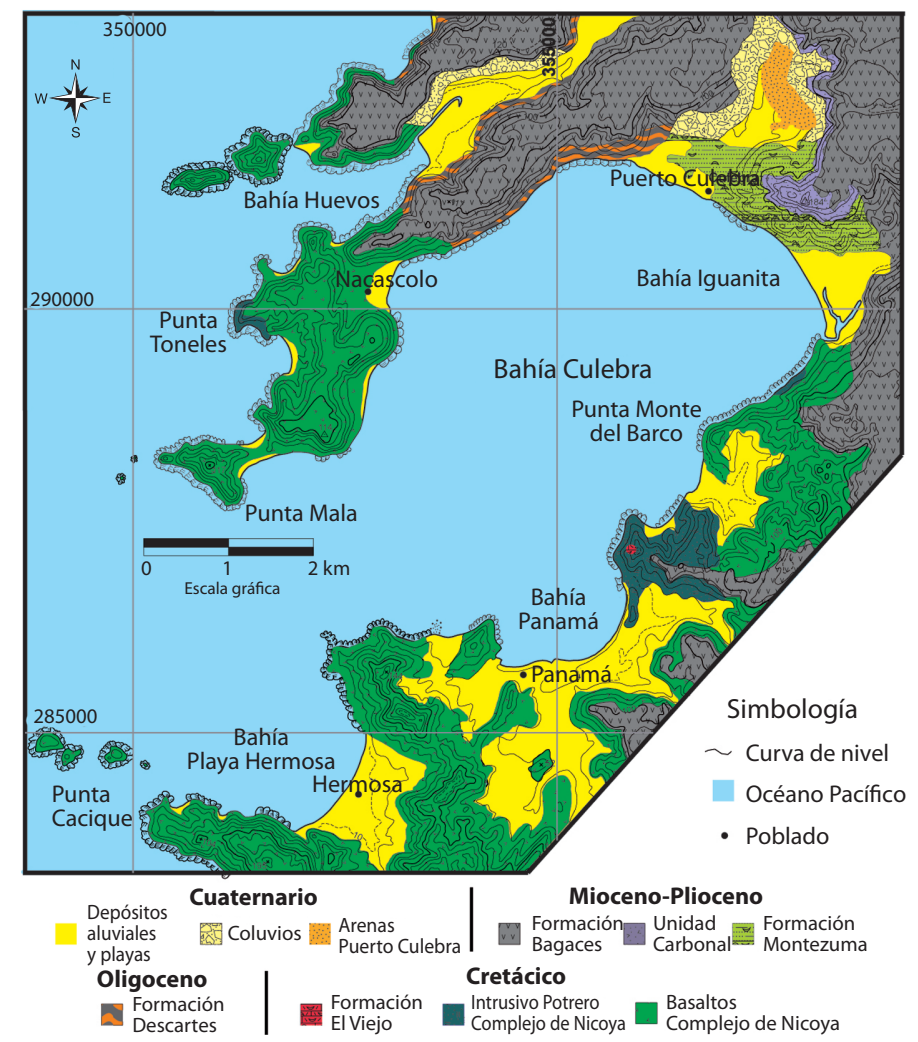

Fig. 2. Mapa geológico de Bahía Culebra.

Fig. 2. Geological map of Bahía Culebra.

unidades de origen ígneo y sedimentario. Posteriormente, Kuijpers $(1979,1980)$ subdivide al Complejo de Nicoya en dos unidades: la inferior ó Unidad Matapalo la cual consiste en basaltos sobreyacidos por radiolaritas, con intrusiones esporádicas de diabasas y gabros ofíticos, los basaltos contienen cuerpos de sulfuros masivos en la parte basal y las radiolaritas presentan intercalaciones de láminas y nódulos de manganeso; la superior ó Unidad Esperanza está formada por basaltos y diabasas ofíticas con intrusiones de gabros y plagiogranitos localmente $y$, hacia la parte superior aparecen unas pocas intercalaciones de radiolarita. $\mathrm{La}$ mayoría de autores han aceptado esta subdivisión. Baumgartner $(1984,1987)$ realiza algunos cambios a esta estratigrafía. Baumgartner (1984) denomina Supergrupo Papagayo a la agrupación de todos los tipos de basamento de composición básica y ultrabásica de origen oceánico, incluyendo sedimentos asociados a procesos tectónicos y/o volcánicos, dentro de este Supergrupo incluye al Complejo de Nicoya junto con la Peridotita de Santa Elena y los Complejos Básicos post-Santonianos. Gursky y Schmidt-Effing (1983) y Wildberg (1984) describen una estratigrafía equivalente a la de Kuijpers (1979, 1980), denominándola Complejo de Nicoya Inferior, Complejo de Nicoya Superior y Formación Punta Conchal, ésta última según Gursky y Schmidt-Effing (1983) agrupa rocas sedimentarias tanto de la Unidad Matapalo como de la Unidad Esperanza.

De acuerdo con Denyer y Baumgatner (2006) y Denyer y Gazel (2009), petrológicamente hablando el Complejo de Nicoya 
pertenece al CLIP (Caribbean Large Igneous Province) y sus rocas ígneas basales se interpretan como una parte remanente de la actividad del punto caliente de Galápagos. El desarrollo del CLIP inicia en el Cretácico Inferior, específicamente durante el Berriasiano-Valanginiano con el emplazamiento de basaltos sobre el piso oceánico que posteriormente fueron sobreyacidos por las capas de radiolaritas; dicha corteza oceánica fue intruida consecutivamente por diques y sills. Con el emplazamiento de intrusiones comienza una circulación termal provocando lixiviados de Mn que se depositan sobre las radiolaritas.

Durante el Turoniano-Coniaciano, basaltos y diabasas cubrieron la secuencia oceánica, provocando que el agua intersticial de las radiolaritas fuera atrapada y sellada en las rocas ígneas, de ésta forma las radiolaritas que no estuvieron en contacto con las rocas ígneas fueron sometidas a deformación, diagénesis acelerada a sílice e hidrofracturamiento; como consecuencia el paquete de radiolaritas se volvió flotante respecto a las intrusiones y las intrusiones al pie del plateau pudieron haberse separado de los sedimentos provocando un efecto similar al de las lámparas de lava. Hacia las últimas fases del Plateou Caribe las aguas hidrotermales ricas en hierro depositan el hidróxido de $\mathrm{Fe}$ diluido junto con sedimentación pelágica de radiolarios, así los depósitos ricos en Fe y en $\mathrm{Si}$ al interactuar con las intrusiones formaron hematita, limonita y jaspe masivo.

Dataciones radiométricas han sido realizadas por Sinton et al. (1997), Hauff et al. (2000), Hoernle et al (2004). Se presentan acá las datataciones realizadas por Denyer y Baumgartner (2006), los cuales determinan la edad de las rocas ígneas mediante dataciones radioisotópicas de $\mathrm{Ar}^{39} / \mathrm{Ar}^{40}$ y concluyen una edad de 83 a 84 Ma para las intrusiones (Santoniano), mientras que para los basaltos una edad de 139 a 88 Ma (Berriasiano-Turoniano); así mismo determinan la edad de las dos facies de radiolaritas mediante biocronología, las radiolaritas ricas en Mn en un rango Jurásico Medio a Cretácico Medio (Bajociano-Albiano) y las radiolaritas ricas en Fe que corresponden con el Cretácico Superior (Coniaciano-Santoniano).

Basaltos: Denyer y Arias (1993) indican que los minerales de alteración del tipo clorita y/o óxidos de hierro son los más frecuentes y, generalmente, se presentan vetillas de calcedonia, ceolitas, ópalo, y rara vez, de calcita.

Camacho et al. (2002) describe a los basaltos como rocas masivas y otras veces en almohadillas; se presentan diferentes sistemas de fracturas, así como fallas que dan origen a formación de arcos. Es notable la acción erosiva del mar en esta unidad, la cual forma nichos de erosión. Según las dataciones $\mathrm{Ar}^{39}$ / $\mathrm{Ar}^{40}$ en Denyer y Baumgatner (2006) los basaltos corresponden con una edad de 139 a $88 \mathrm{Ma}$ (Berriasiano-Turoniano).

Intrusivo Potrero: Denyer y Arias (1993) describen esta unidad por primera vez de forma separada con respecto a los basaltos del Complejo de Nicoya. Está formada por gabros, doleritas y plagiogranitos. Con base en las descripciones de Denyer y Arias (1993), macroscópicamente los gabros son de una coloración oscura con textura porfirítica, rica en minerales máficos con acumulaciones esferoidales centimétricas de piroxenos. Microscópicamente presentan una textura holocristalina-hipidiomórfica-intergranular a ligeramente subofítica con fenocristales de plagioclasa (tipo labradorita), augita titanífera, algunos opacos, rara vez apatito, olivino y comúnmente cloritas y nontronitas (?) como minerales de alteración.

Camacho et al. (2002) describe una textura fanerítica granular con minerales como augitas y plagioclasas. Microscópicamente indican un $40 \%$ de augitas xenomórficas, $25 \%$ de plagioclasas xenomórficas con zonación y $15 \%$ de cuarzo de origen secundario rellenando vetas.

Los plagiogranitos se presentan de forma masiva pero también se pueden observar fracturas. Las rocas son blancas con tonalidades verdes, textura fanerítica porfiritica con fenocristales de plagioclasas, hornblendas y minerales de alteración secundiaria rellenando fracturas. Según Tournon (1994) las vetas de 
plagiogranitos cortan las rocas máficas y se unen en bolsas, son rocas muy ácidas $\left(\mathrm{SiO}_{2}\right.$ : $70 \%$ ) compuesas de cuarzo abundante, plagioclasa y poco anfíbol. Con base a la descripción de Camacho et al. (2002) la textura es fanertíca porfirítica de grano grueso con plagioclasa y hornblendas con vetas rellenas de calcita secundaria.

Como se mencionó anteriormente Denyer y Baumgatner (2006) concluyen mediante datación $\mathrm{Ar}^{39} / \mathrm{Ar}^{40}$ una edad de 83 a 84 Ma para las éstas intrusiones (Santoniano).

Formación El Viejo: Malavassi (1961) menciona presencia de radiolarios en esta Formación: Radiolites sp., Psedorbitoides israelskyi, Sulcoperculina dickersoni y Nerinea epelys. Por su parte, Schmidt-Effing (1974) describe una sección geológica que contiene hacia la base amonites en una lutita fina, con presencia de foraminíreros bentónicos, pero en su mayoría de plantónicos como Gumbelina sp., Pseudotextularia sp., Globigerina sp., también contiene Globotruncana de los grupos lapparenti y ganseri, que indican una edad Campaniana-Maastrichtiana. Hacia la parte media se encuentra una lutita gruesa estratificada con detritos de foraminíferos bentónicos. Hacia el techo de la sección aflora una caliza rica en rudistas, algas rojas, hidrozarios, coralarios y variedad de gatrópodos del género Nerinea. Son abundantes los Raliolites sp., por lo que las calizas tienen una edad Maastrichtiana, más viejas que el Daniano y más jóvenes que el Campaniano (Malavassi, 1961); sin embargo, Seyfried y Sprechmann (1985) con base a la micro fauna estiman la edad de las calizas en el Campaniano Tardío Alto.

Galli y Schmidt-Effing (1977) realizan una descripción más detallada de la fauna de la Formación que incluye: Plecípodos (rudistas y ostreas) presentes con los géneros Antillocaprina, Barrettia, Biradiolites, Duranea, Plagioptychus y Sauvagesia; las algas rojas coralinaceas pertenecientes a los géneros Archacolithothamnium, Lithophyllum y Lithoporella; algas rojas solenoporáceas del género Parachaetetes; equinodermos y macroforaminíferos de los géneros
Amphistegina, Pseudoorbitoides, Rotalia y Sulcoperculina.

Según la descripción anterior SchmidtEffing (1974) clasifica esta Formación como

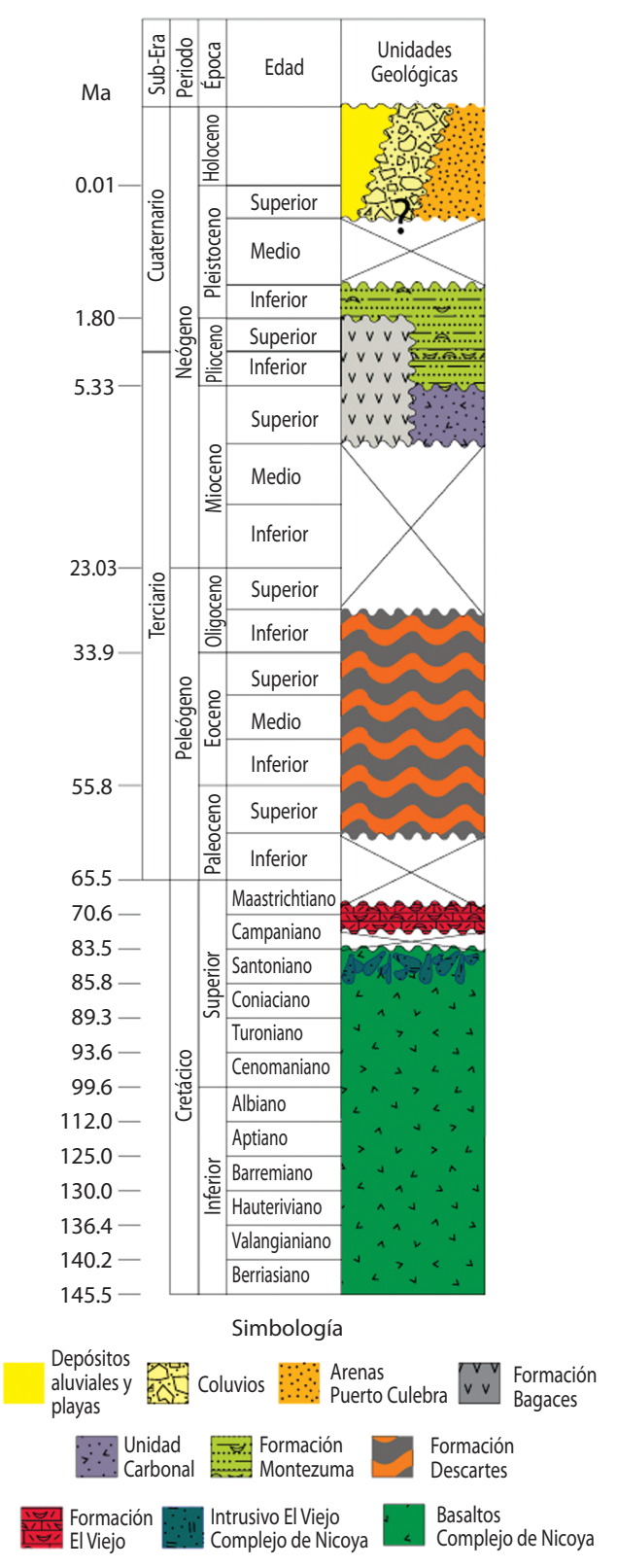

Fig. 3. Columna litoestratigráfica para la región de Bahía Culebra.

Fig. 3. Stratigraphic column for the región of Bahía Culebra. 
calizas arrecifales con facies desde litoral hasta nerítica, contiene sedimentos de organismos calcáreos que vivieron en aguas claras, en movimiento, con una temperatura de $24^{\circ} \mathrm{C}$ y profundidades de entre 40 y $70 \mathrm{~m}$.

Formación Descartes: Astorga (1987) define esta Formación como un sistema depositacional de sedimentos turbidíticos volcaniclásticos y carbonatados, que abarca desde el Paleoceno Superior hasta el Eoceno Superior/ Oligiceno Inferior (Fig. 3). Está conformado por cinco facies desde la parte basal hasta la parte superior: 1) Depósitos de flujo turbulentos lodo-arenosos, representados por areniscas litofeldespáticas, calizas con cemento calcáreo y lutitas de silíceas a carbonatadas, con microfauna plantónica de radiolarios y foraminíferos, presenta bioturbación causada por Chondrites sp., Zoophycos sp., Helmithorhaphe sp., Ophiomorpha sp. y Skolitos sp. 2) Depósitos pelágicos-hemipelágicos, pelitas síliceas estratificadas depositadas por asentamiento pelágico cuando el ambiente turbidítico es nulo. 3) Depósitos de flujo turbulentos arenosos, conformados por areniscas litofeldespáticas con cemento calcáreo y calcarenitas, en una matriz arcillosa con clastos de diámetro variable. 4) Depósitos de flujo turbulentos gravosos, son clastos de origen volcánico, carbonatado nerítico, siliciclástico y/o vulcaniclástico, en una matriz de arenisca. Depósitos de flujo de escombros, consisten en bloques de material turbidítico en una matriz lodo-arenosa muy mal seleccionada. 5) Por último depósitos turbidíticos retrabajados, areniscas con estrarificación gruesa que presentan "foresets" planares de alto y bajo ángulo.

Camacho et al. (2002) describe microscópicamente una muestra de la secuencia correspondiente a una arenisca media a gruesa, clasificada como grauwaca lítica, la cual presenta una matriz compuesta principalmente por óxidos de hierro con un porcentaje de $55 \%$, un $25 \%$ de clastos líticos angulares, $12 \%$ de plagioclasa subangular, $8 \%$ de augita subangular y $1 \%$ de magnetita.
Unidad Carbonal: Lew (1985) la describe como una Formación que consiste en flujos de lodo grises intercalado con areniscas finas calcáreas estratificadas. David (2005) incluye la unidad Carbonal como parte de la Formación Bagaces y corresponde con flujos de lava dacítica a riolítica, cuya mayor característica es la disyunción columnar. Camacho et al. (2002) indica que la unidad está formada por lavas dacíticas y en ocasiones se presenta en forma de pseudoflujos. La roca sana está compuesta de una matriz vítrea de color negro, a veces con pátinas de color morado, contiene fenocristales alargados de plagioclasa, son de color blanco cuando están poco alterados y de color verde cuando se meteorizan. Microscópicamente Camacho et al. (2002) clasifica la roca como dacita, con textura hipocristalina - porfirítica con aproximadamente $75 \%$ de matriz vitrofírica, los fenocristales son básicamente de plagioclasa, hipersteno, augita y magnetita.

Formación Bagaces: Fue descrita por Dóndoli (1950) como una toba gris, pero fue Dengo (1962) quien la definió como una unidad formal constituida por ignimbritas dacíticas y sedimentos lacustres asociados. Tanto Bohnenberger (1968) como Naciones Unidas (1975) dividen a la Formación Bagaces en tres miembros, el miembro inferior de origen lacustre y fluviolacustre; el miembro intermedio que consiste en ignimbritas, lavas y tobas aglutinadas; mientras que el miembro superior consiste en tobas aglutinadas, tobas soldadas y material heterogéneo.

Gillot et al. (1994) la define como una plataforma de ignimbritas que consiste en una secuencia de depósitos de flujos piroclásticos y, en menor medida, flujos de lava intercalados y sedimentos de origen continental sobreyacidos por varios depósitos de flujos de pómez y roca densa equivalente. Chiesa et al. (1992) y Gillot et al. (1994) indican que su edad es de 8 a 16 $\mathrm{Ma}$, es decir, en el rango Mioceno SuperiorPlioceno basados en una datación K-Ar.

Tanto en península de Nacascolo como hacia el este, la Formación Bagaces está representada por una secuencia de flujos piroclásticos 
y depósitos sedimentarios continentales, producto de varias facies o pulsos eruptivos desde la fuente que fueron descritos por Camacho et al. (2002) como unidades informales independientes; la ignimbrita inferior fue descrita como Ignimbrita Estero Palmares, la secuencia volcaniclástica fue descrita como la Unidad Volcaniclástica Cartaga y la Unidad Arenisca Coyol (esta unidad corresponde con el techo de la secuencia sedimentaria continental), seguidamente la Unidad Ignimbritas Nacascolo y finalmente la Unidad Ignimbritas Papagayo.

Formación Montezuma: La primera mención de la Formación la realiza Schaufelberger (1932), posteriormente es descrita sin ser mencionada por Goudkoff y Potter (1942), ya en Hoffstetter et al. (1960) y en Dengo (1962) se describe formalmente como una Formación constituida por areniscas, limonitas y conglomerados. Aguilar y Fischer (1986) describen 130 especies de moluscos presentes en la Formación y Chinchilla (1989) describe a detalle su geología.

Según Chinchilla (1989) la Formación presenta dos tipos de sedimentación distintos: litofacies de origen marino y litofacies de origen continental. Las facies de origen marino corresponden con limos brechosos, areniscas, conglomerados con fauna; las facies de origen continental son arenisca de media a fina bioturbada y conglomerados sin fauna. La sedimentación marina podría considerarse un ciclo simétrico, con regresión en la parte basal y transgresión en la parte superior.

Camacho et al. (2002) describe tres facies: facie de arenisca media fosilífera, facie de arenisca media con laminación cruzada y facies rítmicas de areniscas y lutitas. La facie de arenisca media fosilífera presenta una textura de grano medio, color crema con fósiles de bivalvos, dientes de tiburón, erizos y gastrópodos. La facie de areniscas medias con laminación cruzada se compone de areniscas laminadas con granulometrías medias a gruesas, color gris-crema, con buena selección, buen empaquetamiento y gradación positiva, los componentes son de origen volcánico y los granos se encuentran en contacto puntual y por matriz, se observa una importante laminación cruzada y ripples. La facie rítimica de areniscas y lutitas presenta una alternancia de arenas finas y lutitas intercaladas con areniscas medias, de composición volcánica, color gris oscuro en las lititas y crema en las arenosas, ambas con muy buena selección, con contactos netos entre ellas. Además, se observan estructuras de carga y una importante bioturbación de trazas en forma de tubos de ophiomorpha en posición inclinada respecto a la laminación.

Se determinó una edad Plioceno Inferior-Pleistoceno Inferior mediante dataciones bioestratigráficas con base en los foraminíferos plantónicos analizados en Chinchilla (1989), así como en los moluscos descritos en Aguilar y Fischer (1986).

Arenas Puerto Culebra: Corresponde con una duna de arenas sueltas (no están cementadas) finas a medias de color gris, bien seleccionadas, los granos son redondeados de alta esfericidad. Macroscópicamente resulta difícil determinar la composición de los granos, sin embargo, se puede observar un bajo porcentaje de plagioclasas. Es predominante la laminación horizontal y en algunos sectores se observa laminación cruzada. No se han encontrado fósiles o bioturbación en los afloramientos. No se tienen dataciones de este depósito, sin embargo, por presentar arenas sueltas correspondientes a dunas recientes se infiere que pertenecen al Holoceno.

Coluvios: Texturalmente está compuesta por bloques subangulares de baja esfericidad de arenisca e ignimbritas con diámetros que oscilan entre $10 \mathrm{~cm}$ a $1 \mathrm{~m}$ en una matriz de suelo arenoso-arcilloso. Los contactos son bloque-matriz.

Depósitos aluviales y playas: Corresponde a los depósitos costeros constituidos por las arenas de playa, bermas y dunas formadas por la acción del viento en la zona posterior a algunas playas. Se ha identificado una duna en punta Cacique. También se incluyen los 
depósitos limosos asociados a zonas de manglar, siendo los más representativos el manglar de Iguanita y el manglar de Playa Hermosa. Finalmente, se incluyen los depósitos aluviales de la red hídrica del área de estudio.

\section{CONSIDERACIONES GEOLÓGICAS LOCALES}

Dentro del área de estudio el Complejo de Nicoya presenta dos unidades geológicas constituidas por los Basaltos y el Intrusivo Potrero, descrito por primera vez realizando la separación de de ambas rocas por Denyer y Arias (1993). Los basaltos correlacionables con la unidad Matapalo (Denyer \& Arias 1993), afloran en la zona sur, central y en la península de Nacascolo mientras que el Intrusivo Potrero aflora en la parte central del área de estudio y en punta Toneles.

La edad del Complejo de Nicoya ha sido determinada por distintos métodos tales como dataciones radiométricas, geoquímicas y bioestratigráficas, sin embargo la mayoría de autores concuerda en que oscila entre el Jurásico Inferior y el Cretácico Superior (Denyer \& Baumgartner 2006).

Las rocas de composición basáltica son predominantemente masivas y se observan algunas estructuras en almohadilla en plataformas de abrasión en la península de Nacascolo. El color es verdoso a gris oscuro con una textura afanítica con fenocristales de olivino y fantasmas del mismo mineral, augitas y plagioclasas. Se observan óxidos de hierro y arenitización como producto de la alteración y meteorización de la roca. Presenta vetillas de mineralizaciones secundarias de ceolita y en menor frecuencia de calcita.

Los gabros se caracterizan por ser oscuros y masivos, con una textura fanerítica y de aspecto granular con minerales de plagioclasa y augitas. Posiblemente por su textura granular los productos de meteorización resultan en arenitización de la roca.

La Formación El Viejo está compuesta por calizas con radiolarios Malavassi (1961). En la base contiene amonites y foraminíferos dentro de una lutita (Schmidt-Effing 1974). La parte superior de la Formación presenta una caliza con rudistas como la fauna más representativa y fácil de identificar en el campo.

Los afloramientos de la Formación Descartes descritos en península de Nacascolo corresponden con una secuencia turbidítica con intercalaciones de lutitas y areniscas finas a medias, de colores crema y gris correlacionables con la Facie 4 descrita por Astorga (1987). La composición de las rocas varia de calcárea a volcaniclástica en función de los niveles o secciones de las intercalaciones. La selcción de los granos en cada uno de los estratos es variable, predominando la selección mala a moderada con granos angulares a subangulares de baja esfericidad. Las rocas de grano más fino, constituidas por estratos de lutitas, son friables y fácilmente delesnables. La roca meteorizada presenta colores blancos, café claro y verdosos produciendo formas esferoidales y arcillas secundarias. Como parte de los clastos que están contenidos en la secuencia turbidítica se encontraron dos afloramientos de bloques métricos de calizas, específicametente en las coordanadas Lambert 355590E/291867N y 355257E/291890N. Los bloques son masivos y densos, de diámetros decimétricos a métricos, de color blanco con un cemento calcáreo cristalino y la presencia de estructuras asociadas a algas. Estas calizas son correlacionables con la Formación Barra Honda, nombrada por Dengo (1962) que la describe en dos secciones, la sección inferior formada por calizas duras y de pobre estratificación, y la sección compuesta por calizas de buena estratificación. La presencia de calizas de Barra Honda pueden ser el resultado del desprendimiento y caída de bloques desde la plataforma donde crecieron las comunidades coralinas hacia el talud continental. Según Calvo (1987) partes de la plataforma carbonatada de la Formación Barra Honda fueron resedimentadas tectónica o sedimentariamente encontrándose sobre sedimentos de edad Paleoceno.

Las dacitas de la Unidad Carbonal forman estructuras en flor debido a la disyunción con un eje central del cual derivan las columnas. 


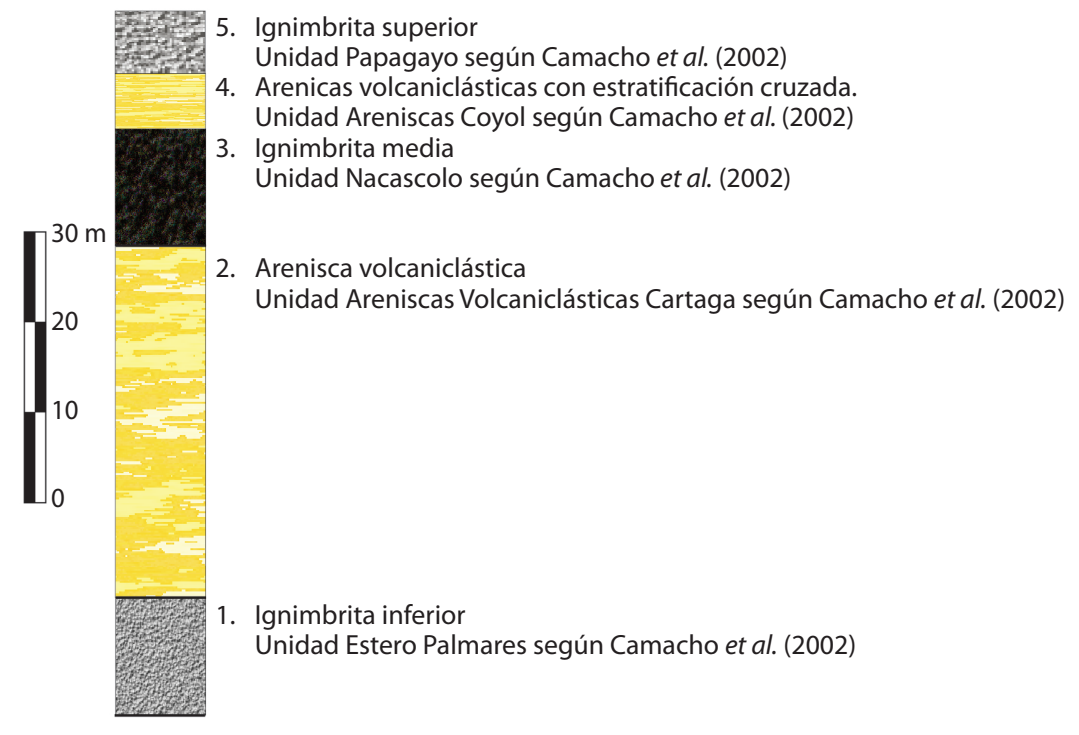

Fig. 4. Distribución estratigráfica de las facies de la Formación Bagaces en la Península de Nacascolo.

Fig. 4. Stratigraphic distribution of Bagaces Formation’s facies in Nacascolo Peninsula.

Estas estructuras son complejas y a lo largo de los afloramientos se pueden observar diferentes inclinaciones de las columnas así como sus líneas de flujo. En algunos sectores de la unidad se observan brechas con fragmentos dacitas y una matriz de líticos con mayor grado de fragmentación.

En Península de Nacascolo se identificaron tres eventos de flujos piroclásticos y dos secuencias de areniscas volcaniclásticas empaquetada en la secuencia ignimbrítica asociado a la Formación Bagaces (Fig. 4). Partiendo de la base de dicha secuencia se describe: 1) Ignimbrita con textura ignimbrítica fluidal con fiames de obsidiana, fragmentos líticos no juveniles de lavas andesíticas, fragmentos líticos juveniles de andesitas, cristales de plagioclasa y piroxenos. Todos los elementos se encuentran en una matriz gris oscuro de ceniza. La roca se encuentra soldada, muy consolidada y sana con pátinas de meteorización menores a $1 \mathrm{~mm}$ de espesor. 2) Sobreyace a la ignimbrita ubicada en la base un depósito volcaniclástico de arenisca de grano fino a grueso con fragmentos subangulares a subredondeados de baja esfericidad, con contactos granograno y grano-matriz con mala selección. Está compuesta posiblemente por granos de lavas y/o ignimbritas indeterminadas. Las capas de la arenisca presentan gradaciones positivas y negativas, donde los granos van disminuyendo o aumentando de tamaño desde la base hacia el estrato superior. Presenta pátinas de meteorización superficial color beige en algunos afloramientos. En la parte superior de la unidad la meteorización ha sido muy intensa por influencia directa del agua y se calcula una zona de 1 a 3 metros de roca alterada a arcillas. Se calcula un espesor mayor a $40 \mathrm{~m}$ para esta secuencia sedimentaria continental. 3) Sobreyaciendo el depósito de areniscas aflora una ignimbrita con textura ignimbrítica fluidal con fantasmas de fiames que podrían corresponder a pómez ya meteorizadas, fragmentos líticos no juveniles de lavas indeterminadas, cristales de plagioclasa y una matriz soldada y densa color gris claro. Una característica de ésta facie ignimbrítica es que en algunos sectores se identifican columnas hexagonales producto del enfriamiento del depósito. 4) Continuando con las facies de la Formación Bagaces, aflora en algunos sectores de la península de Nacascolo otro paquete de areniscas volcaniclásticas de grano fino a grueso, mal seleccionada y con 
estratificación cruzada. 5) Finalmente, en la parte superior de la secuencia aflora una ignimbrita de textura ignimbrítica fluidal con fiames de pómez negras de hasta $30 \mathrm{~cm}$ de largo, fragmentos líticos no juveniles de lavas andesíticas con cristales de plagioclasa, fragmentos líticos juveniles de lavas andesíticas con cristales de plagioclasa y piroxenos, poros con pátinas de óxidos de hierro y algunos fiames de obsidiana pero en muy bajo porcentaje. Todos los elementos se encuentran en una matriz gris oscuro de ceniza. La roca se encuentra soldada y muy consolidada. La meteorización se muestra en pátinas crema a amarillo menores a $1 \mathrm{~mm}$ de espesor.

Las rocas de la Formación Montezuma corresponden a facies sedimentarias someras de conglomerados, limos y areniscas y, facies continentales que incluyen areniscas y lutitas con estratificación y laminaciones. En la matriz de las rocas se puede identificar diferentes especies de fauna tales como moluscos (Aguilar \& Fischer 1986).

En el techo de la litoestratigrafía de la zona de Bahía Culebra afloran las rocas más jóvenes, vinculadas a procesos erosivos y de depositación eólica o aluvial. Muestra de ello son las arenas Puerto Culebra, coluvios compuestos por bloques angulares mayoritariamente de ignimbritas y los depósitos aluviales y costeros.

\section{AGRADECIMIENTOS}

A los geólogos Percy Denyer, Daniel Murillo y Douglas Camacho por sus recomendaciones y consultas durante la elaboración de la investigación. Un agradecimiento especial a Andrey Villegas por la colaboración para traducir el texto del abstract.

\section{RESUMEN}

La geología de Bahía Culebra, Guanacaste, Costa Rica, está compuesta por rocas volcánicas de corteza oceánica; sedimentos marinos depositados en el talud, la plataforma continental y zonas someras cerca de la costa; secuencias de rocas piroclásticas intercaladas con sedimentos continentales y depósitos Cuaternarios recientes. En la base de la secuencia estratigráfica afloran los basaltos masivos, algunas veces en almohadilla, del Complejo de Nicoya con textura afanítica con fenocristales de olivino, augitas y plagioclasas. Dentro de la misma Formación se incluyen intrusivos de gabro masivos con piroxenos y plagiogranitos con fenocristales de plagioclasas y hornblenda. Seguidamente afloran las calizas de la Formación El Viejo constituida por colonias arrecifales e intercalaciones calcáreas. La Formación Montezuma compuesta por facies de arenisca media fosilífera, facies de arenisca media con laminación cruzada y facies rítmicas de areniscas y lutitas. Las Dacitas Carbonal están compuestas por lavas hexagonales y variaciones brechosas con clastos de pómez y minerales de alteración. La Formación Bagaces se constituye de varios eventos eruptivos con secuencias de ignimbritas y un depósito sedimentario posiblemente pluvial de arenas volcaniclásticas. En la parte superior de la secuencia estratigrafica se incluyen los depósitos producto de factores erosivos tales como coluvios, arenas de playa, sedimentos de zonas de manglar y aluviones.

Palabras clave: Bahía Culebra, geología, Costa Rica.

\section{RERERENCIAS}

Astorga, A. 1987. El Cretácico Superior y el Paleógeno de la vertiente pacífica de Nicaragua meridional y Costa Rica septentrional: origen, evolución y dinámica de las cuencas profundas relacionadas al margen convergente de Centroamérica. Tesis de Lic., Univ. Costa Rica, San Pedro, san José, Costa Rica.

Aguilar, T. \& R. Fischer. 1986. Moluscos de la Formación Montezuma. Geol. Palaeontolog. 20: 209-241.

Arias, O. \& P. Denyer. 1992. Mapa geológico de la hoja Carrillo Norte, Guanacaste, Costa Rica. Escala 1:50 000. Instituto Geográfico Nacional, San José, Costa Rica.

Baumgartner, P. 1987. Tectónica y sedimentación del Cretácico superior en la zona pacífica de Costa Rica (América Central). Simp. Int.: El Cretácico de México y América Central. Linares, México: 251-260.

Baumgartner, P., C. Mora, J. Butterlin, J. Sigal, G. Glacon, J. Azéma \& J. Bourgois. 1984. Sedimentación y paleogeografía del Cretácico y Cenozoico del litoral pacífico de Costa Rica. Rev. Geól. Am. Central 1: 57-136.

Bohnenberger, O.H. 1968. Un reconocimiento fotogeológico en Guanacaste. Informe Interno, Naciones Unidas, San José, Costa Rica.

Camacho, D., I. Chaves, M. Alvarado, J. Chaves, M. Gómez, D. Murillo \& M. Vásquez. 2002. Geología, geotecnia y amenazas naturales de una parte de las 
hojas Ahogados y Carrillo Norte. Inf. Campaña Geol., Univ. Costa Rica, san Pedro, San José.

Chiesa, S., G. Civelli, P. Gillot, O. Mora \& G.E. Alvarado. 1992. Rocas piroclásticas asociadas con la formación de la Caldera de Guayabo, Cordillera de Guanacaste, Costa Rica. Rev. Geol. Amér. Central 14: 59-75.

Chinchilla, A.L. 1989. Estudio Geológico de la Formación Montezuma (Plio-Pleistoceno), Península de Nicoya, Costa Rica. Inf. Campaña Geol., Univ. Costa Rica, San Pedro, San José.

David, A. 2005. The Bagaces Formation in the Guanacaste Province, Costa Rica; refined stratigraphy and petrology. IFM-GEOMAR, Kiel, Alemania.

Dengo, G. 1962. Estudio Geológico de la Región de Guanacaste, Costa Rica. Instituto Geográfico Nacional, San José, Costa Rica.

Denyer, P. \& O. Arias. 1993. Geología del norte de la Península de Nicoya, Costa Rica. Rev. Geol. Amér. Central 16: 69-84.

Denyer, P. \& P.O. Baumgartner. 2006. Emplacement of Jurassic-Lower Cretaceous radiolarites of the Nicoya Complex (Costa Rica). Geol. Acta 4: 203-218.

Denyer, P. \& E. Gazel. 2009. The Costa Rica Jurassic to Miocene oeanic complexes: origin, tectonics and relations. J. South Amer. Earth Sci. 28: 429-442.

Dondoli, C. 1950. Liberia y sus alrededores. Bol. Técn. Minist. Agric. Industr. 3: 1-8.

Galli, C. \& R. Schmidt-Effing. 1977. Estratigrafía de la cubierta sedimentaria supra-ofiolítica Cretácica de Costa Rica. Ciencia y Tecnología 1: 87-96.

Gazel, E., P. Denyer \& P.O. Baumgartner. 2006. Magmatic and geotectonic significance of Santa Elena Peninsula, Costa Rica. Geol. Acta 4: 193-202.

Gillot, P., S. Chiesa \& G. Alvarado. 1994. Chronostratigraphy of Upper Miocene-Quaternary volcanism in Northern Costa Rica. Rev. Geol. Amér. Central 17: 45-53.

Goudkoff, P.P. \& W.W. Potter II. 1942. Amoura shale, Costa Rica. Bull. Amer. Ass. Petrol. Geol. 26: 1647-1655.

Gursky, H.-J. \& R. Schmidt-Effing. 1983. Sedimentology of radiolites within the Nicoya Ophilite Complex, Costa Rica. Develop. Sediment. 36: 127-142.

Hoffstetter, R., G. Dengo, R. Weyl, C.G. Dixon, H. MeyerAbich, P. Woodring \& L. Zoppis. 1960. Lexique Stratigraphique International-Amérique Latine Fascicule IIa: Amerique Centrale. Centre National, París.
Jaccard, S., M. Munster, P. Baumgartner \& C. Mora. 2001. Barra Honda (Upper Paleocene-Lower Eocene) and El Viejo (Campanian-Maastrichtian) carbonate platforms in The Tempisque Area (Guanacaste, Costa Rica). Rev. Geol. Amér. Central 24: 9-27.

Kuijpers, E.P. 1979. La geología del Complejo Ofiolítico de Nicoya, Costa Rica. Informe Semestral, Instituto Geográfico Nacional, San José, Costa Rica.

Kuijpers, E.P. 1980. The geologic history of the Nicoya Ophiolite Complex, Costa Rica, and its geotectonic significance. Tectonophysics 68: 233-255.

Lew, L. 1985. The geology of the Santa Elena Peninsula, Costa Rica, and its implications for the tectonic evolution of the Central America-Caribbean Region. $\mathrm{PhD}$, Pennsylvania State University, State College, Pennsylvania.

Malavassi, E. 1961. Some Costa Rican larger forminiferal localities. J. Paleontol. 35: 498-502.

Meschede, M., M. Sick \& W. Frisch. 1988. Interpretación geodinámica de los Complejos Ofiolíticos de Costa Rica. Rev. Geol. Amér. Central 8: 1-18.

Mora, S. 1978: Estudio geológico de los cerros Barra Honda y alrededores. Tesis de Lic., Escuela de Geología, Univ. Costa Rica, San Pedro, San José.

Murillo, D. 2008. Aplicación ambiental del método de resistividad eléctrica en el modelado del acuífero costero en playa Panamá, Guanacaste, Costa Rica. Rev. Geol. Amér. Central 38: 21-31.

Naciones Unidas. 1975. Investigaciones de aguas subterráneas en zonas seleccionadas: Costa Rica. Informe Interno, Naciones Unidas, San José.

Schaufelberger, P. 1932. Un estudio elemental sobre la geología de Costa Rica. La Escuela Costarricense 3, San José, Costa Rica.

Schmith-Effing, R. 1974. El primer hallazgo de amonites en América Central Meridional y notas sobre las facies Cretácicas en dicha región. Informe Semestral, Instituto Geográfico Nacional, San José, Costa Rica.

Tournon, J. 1994. The Santa Elena Peninsula: an ophiolitic nappe and a sedimentary volcanic relative autochthonous. Profil 7: 87-96.

Wilberg, H. 1984. Der Nicoya-Komplex, Costa Rica, Zentralamerica: magmatismus und genese eines polygenetischen Ophiolith-Komplaxes. Forsch. Geol. Paläont. 62: 1-123. 
